\title{
COMUNICAÇÃO ORGANIZACIONAL PÚBLICA: INFLUÊNCIAS E DESAFIOS
}

\author{
João Cubas Martins ${ }^{1}$ \\ Liliane Canopf ${ }^{2}$
}

\begin{abstract}
Resumo: Este artigo discute a comunicação organizacional em instituições públicas. Por meio de revisão bibliográfica sobre o assunto, busca-se compreender o potencial estratégico da comunicação dentro das organizações. $O$ trabalho procura apontar, por meio de exemplos, como a comunicação tem sido entendida nas organizações, em especial, nas públicas; a influência da perspectiva política nas assessorias de comunicação; e como são exercidas as influências de gestores e usuários. Mostra-se o contexto de ambientes abertos ao diálogo e de outros com falhas de comunicação, além do conhecimento necessário ao profissional que atuará nas assessorias, sob o contexto organizacional. Conclui-se que o presente estudo é incipiente e que novas pesquisas podem complementar e aprofundar o entendimento sobre o papel estratégico da comunicação em organizações públicas.

PALAVRAS-CHAVE: Comunicação organizacional. Organizações públicas. Assessoria de comunicação.
\end{abstract}

\section{PUBLIC ORGANIZATIONAL COMMUNICATION: INFLUENCES AND CHAL- LENGES}

\begin{abstract}
This article discusses the organizational communication in public institutions. Through a bibliographic review on the subject, seek to understand the strategic potential of communication within organizations. The work seeks to point out, through examples, how communication has been understood in organizations, especially in public ones; the influence of the political perspective on communication consultants; and how the influences of managers and users are exercised. The context of environments open to dialogue and others with communication failures is shown, in addition to the knowledge needed by the professional who will work in the consultancies, under the organizational context. It is concluded that the present study is incipient, and that new research can complement and deepen the understanding of the strategic role of communication in public organizations.
\end{abstract}

KEYWORDS: Organizational communication. Public organizations. Communication advice.

\section{COMUNICACIÓN ORGANIZACIONAL PÚBLICA: INFLUENCIAS Y DESAFÍOS}

Resumen: Este artículo discute la comunicación organizacional en las instituciones públicas. Mediante una revisión bibliográfica sobre el tema, busque comprender el potencial estratégico de la comunicación dentro de las organizaciones. El trabajo busca señalar, ejemplos de cómo se ha entendido la comunicación en las organizaciones, especialmente en las públicas; la influencia de la perspectiva política en los consultores de comunicación; y cómo ejercen las influencias de los gerentes y usuarios. Se muestra el contexto de entornos abiertos al diálogo y otros con fallas de comunicación, además del conocimiento que necesita el profesional que trabajará en las consultorías, en el contexto organizacional. Se concluye que el presente estudio es incipiente y que las nuevas investigaciones pueden complementar y profundizar la comprensión del papel estratégico de la comunicación en las organizaciones públicas.

PALABRAS CLAVE: Comunicación organizacional. Organizaciones públicas. Consejos de comunicación.

\section{Introdução}

A comunicação organizacional é uma área de estudo que alia conhecimentos das ciências administrativas com os da comunicação. A demanda da sociedade por dados públicos de forma transparente aumenta ao mesmo tempo em que os montantes de investimento público são mais

\footnotetext{
${ }^{1}$ Relações Públicas da Universidade Federal do Paraná. Graduado em Relações Públicas (PUCPR), em Jornalismo (UFPR) e Mestre em Administração Pública (UTFPR). Atua na comunicação do Setor de Ciências Biológicas da UFPR, com ênfase em Comunicação Científica, Cultural e Organizacional.

${ }^{2}$ Professora da Universidade Tecnológica Federal do Paraná- UTFPR, atua na graduação e pós-graduação em Administração. Graduada em Administração e em Teologia, Mestre em Gestão de Negócios, Doutora e Pós-doutora em Administração. Desenvolve Pesquisa em Administração e Estudos Organizacionais, principalmente nos temas Ensino em Administração, Emoção, Prática, Subjetividade e Pesquisa Qualitativa.
} 
escassos. Por essa razão, torna-se necessário trazer, tanto ao público interno quanto ao externo, as informações de como estão sendo executados os programas e políticas das organizações públicas. Assim, promove-se a interação e o diálogo entre a organização e o público, produz-se transparência e contribui-se com a efetividade dos serviços dessas organizações. A importância dos processos de democratização e transparência nas comunicações também se evidencia quando é necessário transformar a realidade e a imagem das organizações. Por esse motivo, a comunicação pode ser importante instrumento de esclarecimento à população em momentos de dificuldades, tanto com a opinião pública quanto com investidores e outros públicos de influência.

O objetivo geral do artigo é realizar uma revisão bibliográfica dos estudos relativos à comunicação organizacional em instituições públicas. Os objetivos específicos são: verificar quais são as dificuldades na consecução dos serviços de comunicação, as influências dos ambientes político e cultural nos serviços e; verificar os conceitos da assessoria de comunicação alinhados ao contexto organizacional.

Serão apresentados os princípios e os objetivos da comunicação organizacional, exemplos de estudos já realizados em instituições públicas e os requisitos que as assessorias de comunicação devem apresentar para promover uma comunicação eficiente, tanto em relação às aptidões dos profissionais quanto ao ambiente em que estas assessorias estão inseridas

Para alcançar os objetivos descritos, foi realizada revisão bibliográfica do assunto em livros, dissertações e artigos. Após a definição das palavras-chave, foram feitas consultas à base de periódicos da Coordenação de Aperfeiçoamento de Pessoal de Nível Superior (CAPES), condizentes com as áreas de conhecimento delimitadas para a pesquisa. O levantamento resultou em um portfólio no qual está baseada a bibliografia deste artigo.

\section{A Comunicação nas Organizações Públicas}

Vos e Westerhoud (2008) afirmam que a comunicação é uma das formas mais importantes de as instituições promoverem a democracia através da participação, interação e confiança. No entanto, a pesquisa sobre a comunicação de organizações tem sido limitada e dispersa por várias disciplinas. Ainda segundo as autoras, nos últimos anos houve um interesse crescente pelo assunto.

O objetivo da comunicação é fornecer aos cidadãos informações relevantes para que possam cumprir as suas obrigações de cidadãos e eleitores (DEVERELL et al., 2015). No contexto empresarial, cabe aos colaboradores buscar saber das suas obrigações dentro do espaço organizacional e conhecer os espaços de participação, onde podem reivindicar direitos e conhecer os ser- 
viços oferecidos. Dessa forma, os canais de comunicação têm este papel de esclarecer os empregados sobre seus direitos e deveres.

A meta da comunicação organizacional é posicionar a instituição estrategicamente em relação a outros atores, a fim de ganhar e manter uma reputação vantajosa, legitimidade e recursos. Deste modo, aparência e percepção têm prioridade sobre os fatos objetivos, legitimidade e aceitação (DEVERELL et al., 2015). Neste sentido, há de se atentar que o objetivo da comunicação não é apenas este, mas também o de promover o diálogo com a comunidade. A divulgação e popularização do conhecimento produzido pelas instituições por meio da comunicação pode ser um fator determinante para esta promoção de diálogo.

Os princípios que regem a comunicação pública são a participação, a deliberação e o diálogo. Os cidadãos são vistos como parceiros, em vez de sujeitos ou clientes, o que implica uma dispersão do poder. As práticas consistem em múltiplos canais de duas vias, com base nos princípios de participação igualitária em discussões. Na comunicação pública, a Internet torna-se a interface preferida (DEVERELL et al., 2015).

Neste contexto, é importante manter canais de diálogo - tanto os eletrônicos quando os tradicionais, como o e-mail e os informativos impressos, além da comunicação administrativa presente na comunicação formal das instâncias deliberativas e consultivas - para que o público possa se informar sobre o que ocorre na organização.

De acordo com Canel e Sanders (2012), as organizações públicas estão mais sujeitas a sanções e controles em conformidade com as expectativas do interesse público. Ainda segundo as autoras, as considerações políticas, eventos e recursos estruturais da cultura, de pessoal e de metas influenciam na comunicação organizacional. Por esta razão, cabe à assessoria de comunicação entender a pluralidade dos públicos que podem ser influenciados pela comunicação.

Neste sentido, em relação às estruturas e processos, as organizações do setor público tendem a ser mais complexas do que suas contrapartes do setor privado. Há mais diversidade e incerteza. Os efeitos de uma tomada de decisão podem ser mais amplos do que em estruturas privadas. Apesar de serem fiscalizadas pelo governo e de prestarem serviços à população, as autarquias $^{3}$ - como as universidades federais, agências reguladoras e entidades - são órgãos públicos autossuficientes e detêm o poder de se autogerirem. Strelow (2015) acredita que essa parcela de autonomia é importante para garantir que estudos de comunicação reflitam menos uma política comunicacional partidária e mais a realidade complexa dessas organizações e dos profissionais que as compõem.

\footnotetext{
${ }^{3}$ As autarquias são entidades que detêm autonomia, criada por meio de lei específica, que possuem personalidade jurídica de direito público, com patrimônio próprio e com atribuições estatais (COSTA, 2012).
} 
Como reflexo da autonomia, cabe aos profissionais da área de comunicação o desafio de estimular o diálogo e qualificar o processo comunicacional. O comunicador precisa trabalhar a cultura organizacional por meio da adoção de estratégias de promoção do fluxo contínuo e multidirecional de comunicação. Como resume Marchiori (2008, p. 316), “[...] devemos assumir a função de catalisadores, provedores e disseminadores de conteúdo, criando novos ambientes internos”. Nesse ínterim, Luiz Carlos Iasbeck (2013), reforça que as organizações são o conjunto de indivíduos que reúnem esforços (por interesses individuais e/ou coletivos) para concretização de projeto coletivo através de um sistema de troca de informações, caracterizado como Comunicação Organizacional.

Para Torquato (2004), a comunicação organizacional engloba outras três formas de comunicação, podendo ser definidas como comunicação cultural (que comporta os climas internos); comunicação administrativa (que reúne os papéis, as cartas internas, os memorandos); e comunicação social (envolvendo as áreas de jornalismo, relações públicas, publicidade, editoração e marketing). Ainda para Torquato (2004) existe uma quarta forma de comunicação, que seriam os sistemas de informação, que agregam as informações armazenadas em bancos de dados. Como se vê, várias unidades administrativas, não somente a responsável pela comunicação em si, praticam a comunicação organizacional. Sob o aspecto das assessorias de comunicação em ambiente público, a atividade empregada engloba com mais ênfase as classificações cultural e social, na medida em que, noticiando e contatando diferentes atores organizacionais, pode perceber se a comunidade se sente representada e integrada.

À luz dos conceitos de comunicação, a dificuldade em estabelecer uma definição para a comunicação pública também está relacionada à diversidade do campo de atuação (ALVES, 2015). Alguns estabelecem como parâmetro a busca por preservação e melhoria da imagem institucional, outros a garantia da informação ao cidadão e a prestação de contas à sociedade. O aspecto político também é delineado com ações vinculadas ao interesse coletivo e não aos interesses do governo ou interesses partidários.

É possível ainda acrescentar que o processo da comunicação está relacionado a questões socioculturais organizacionais e, assim, o objeto de análise concentra-se nos elementos formadores dos climas internos. Ou seja, o diagnóstico amplo das situações internas, de acordo com as perspectivas sociológicas e antropológicas, é imprescindível para a implantação de projetos comunicacionais (TEGONI, 2015).

Na proposição destes projetos, Marchiori (2012) aponta que, ao se pensar a organização como espaço de interação e relações, deve-se levar em conta a estrutura que serve como base 
para a realização de ações. É necessário observar que a presença de interações fundamenta e influencia a ação conjunta entre departamentos e setores organizacionais.

Verifica-se ainda que, em organizações públicas, os colaboradores têm necessidades individuais e coletivas, cabendo à instituição identificar estas variáveis e promovê-las no intuito de estimular o comportamento motivacional, aspecto relevante para o clima e desempenho organizacional. A comunicação interna formal emerge como instrumento viabilizador deste processo (SILVA et al., 2012). Partindo desse contexto, os profissionais que se propõem a planejar e a coordenar a comunicação de uma organização necessitam realizar um diagnóstico da cultura organizacional (BALDISSERA, 2000), estando ela implícita ou explícita nas redes formais e/ou informais. Objeto cobiçado pelos gestores que na hierarquia possuam poder, a comunicação organizacional pode se transformar em processo de manipulação, tanto de interesses pessoais quanto como transmissora do pensamento organizacional - missão, visão, valores, filosofia e políticas que representam a cultura da empresa (CRUZ, 2007). Por essa razão, é fundamental estabelecer uma clara definição do papel da comunicação, que, mais do que ressaltar a imagem de determinado gestor, precisa estar sintonizada com a comunidade em que está inserida.

Pode-se dizer também que a comunicação organizacional seja orientada por uma tendência dos órgãos governamentais de realizar uma comunicação alinhada não somente para o atendimento dos interesses da organização e de seus gestores (coalizão dominante, corporações, políticos), mas também direcionada ao atendimento dos interesses do conjunto da sociedade de forma estratégica (GERZSON e MÜLLER, 2009).

Um dos aspectos que reflete o desinteresse de algumas organizações pela comunicação organizacional é o número de profissionais envolvidos na atividade. Reinaldo, Mayer e Nogueira. (2010) fizeram um estudo na estrutura do Instituto Nacional do Seguro Social (INSS) no Estado de São Paulo e constataram que, no período estudado, havia apenas 148 profissionais atuando oficialmente na área de comunicação (menos de $0,5 \%$ do total de servidores ativos). De acordo com os autores, a comunicação, à época da pesquisa, era a área do INSS com menor número de funcionários. Isso comprova que a quantidade de servidores alocados em serviços de comunicação é muito baixa. Outro exemplo vem da Universidade Federal do Paraná (UFPR). Dados consultados em maio de 2017 apontam que, dos 5.290 servidores técnico-administrativos, apenas seis eram jornalistas, cinco eram revisores de texto e um, relações públicas. Esse quantitativo resulta em $0,22 \%$ do total de servidores ativos na Universidade.

Frente à aparente dificuldade em suprir a demanda de pessoal, Gerzson e Müller (2009), indicam que as instituições têm adotado iniciativas inusitadas para dar conta do investimento em comunicações. Os profissionais da área e as instituições de ensino incorporam em suas ações 
perspectivas de valorização humana, ambiental, social, cultural, passando a empregar recursos mais econômicos, dirigidos pontualmente para cada público.

A fim de acompanhar a agilidade das demandas, como as apresentadas até agora, novas práticas são incorporadas ao repertório dos profissionais e pesquisadores da área que se debruçam sobre a ação e a gestão da comunicação. Assim como o ambiente externo traz a constante necessidade de evolução, a imagem da administração pública perante os cidadãos também é alvo de preocupação (GERZSON e MÜLLER, 2009). Outro enfoque que pode justificar o uso da comunicação institucional pública é o retorno dos investimentos dos governos e a divulgação de como estão sendo aplicados. Certamente, a percepção não só do investimento, mas de visibilidade dos projetos realizados e, por consequência, da instituição, é importante para a transparência pública.

A comunicação também tem característica educativa. Em meio à diversidade de informações veiculadas, é factível que o aprendizado aconteça e que a reflexão gere conhecimento pois, com a comunicação, por exemplo, é possível conhecer realidades distantes geograficamente, mas que podem representar motivação para a mudança local. O conhecimento de outras culturas configura oportunidade para melhoria nas condições de vida da sociedade (ALVES, 2015).

A importância da comunicação nas instituições públicas está diretamente relacionada à responsabilidade do Estado perante a sociedade (ALVES, 2015). A Constituição Federal, no artigo 37, apresenta como um dos fundamentos da administração pública um item relacionado à área: “A administração pública direta e indireta de qualquer dos Poderes da União, dos Estados, do Distrito Federal e dos Municípios obedecerá aos princípios de legalidade, impessoalidade, moralidade, publicidade e eficiência” (BRASIL, 1988). O princípio da publicidade, explicitado na Constituição, é a base fundamental para todo o trabalho dentro de qualquer instituição pública - o de prestar contas à sociedade e mostrar a eficiência da instituição.

Para analisar o cenário em que a comunicação está inserida, de acordo com Alves (2015), é necessário verificar se a comunicação é concebida de forma estratégica, global, de longo prazo ou representa somente ações isoladas e desfragmentadas. É preciso analisar se o setor influencia e é influenciado pela estratégia adotada pela organização.

\section{Comunicação Enquanto Estratégia}

A comunicação organizacional, em uma perspectiva abrangente como apontada por Kunsch (2010), é, por si só, complexa. Para a autora, a área de comunicação deixa de ter uma função meramente tática e passa a ser considerada estratégica, isto é, ela precisa agregar valor às organizações, ajudá-las no cumprimento de sua missão, na consecução dos objetivos globais, na 
fixação pública de seus valores e nas ações para atingir seu ideário de visão no contexto de uma visão de mundo, sob a égide dos princípios éticos. Nassar (2005), também considera que a comunicação se torna estratégica quando a instituição estabelece diálogos a respeito de suas políticas, suas ações e suas pretensões; informa, organiza e reconhece os seus públicos de interesse, entre os quais os seus colaboradores; legitima a sua existência; e trabalha pela melhoria do ambiente de trabalho, entre outros objetivos. Por essa razão, as ideias não podem ser isoladas e canais de interação dialógicos, que viabilizem o retorno dos seus consumidores sobre o material e os assuntos veiculados e a interação entre estes e o emissor, precisam estar presentes para que as necessidades de cada público possam ser atendidas.

Sob esta ótica, Bakhtin (1992 apud IASBECK, 2012) afirma que o discurso está ligado as condições sociais da comunicação. De acordo com o autor, uma ideia, qualquer que ela seja, não sobrevive sem dialogar com as ideias dos outros. Em um ambiente em que o diálogo acontece, Roman (2012) divide os discursos entre os bem-ditos e os mal-ditos. Os discursos bem-ditos são as mensagens organizadas pelos canais oficiais - intranet, e-mail, comunicados, houseorgans ${ }^{4}$, mural. Neste discurso o destinatário das mensagens é o funcionário, reconhecido como um profissional que estabeleceu uma relação de trabalho com a organização. Nas mensagens é motivado a integrar-se aos objetivos da organização. Já os discursos mal-ditos são as chamadas "rádiocorredor", "rádio-peão", entre outros nomes. Propagam-se em velocidade rápida e vocabulário singelo, oral. Ainda de acordo com o autor, mais do que distinguir esses dois discursos, é necessário entender as características de interação da comunicação nas organizações e como as pessoas participam simultaneamente desses dois discursos.

Emprestando esse conceito aos ambientes da administração pública, pode-se ampliar o universo não somente aos empregados, mas também aos usuários dos serviços públicos. Enxergar como essas comunicações informais se estabelecem e quais os assuntos que estão sendo discutidos nas instâncias formal e informal pode clarear o entendimento da recepção à comunicação organizacional. O autor fala de e-mails, mas também há os grupos de Whatsapp, Facebook e páginas na Internet, que podem ser um termômetro de como a instituição é percebida por estes públicos.

Roman (2012, p. 145) denomina "organização dialógica como qualquer comunidade de trabalho em que se vivencia e se promove a harmônica convivência conflituosa entre os discursos bem-ditos e os mal-ditos, com a consequente redução dos mal-ditos”. Nesse sentido, Marchiori (2012) diz que agir somente como comunicadora de fatos ocorridos (função informativa) não sustenta mais a atividade da comunicação organizacional. É preciso que a comunicação assuma 
também a posição de geradora dos fatos, criadora de contextos, o que sugere um novo comportamento, na medida em que é cocriadora do futuro da organização.

A mesma autora reforça o sentido da comunicação como construtora da realidade quando diz que é necessário atuar não apenas no sentido de selecionar informações que façam parte do contexto vivenciado pela empresa. "É preciso que as informações tenham sentido para todos os públicos, olhar a comunicação como possibilidade de (re) construção. Assim, a comunicação será um processo real.” (MARCHIORI, 2008, p.28).

\section{O Papel das Assessorias na Comunicação Organizacional}

A comunicação organizacional pública opera em um ambiente político. Isso geralmente leva, em curto prazo, a considerações que podem interferir nas atividades comunicacionais. Os chefes de comunicação nos ministérios, agências e instituições podem ser nomeados baseados em critérios mais partidários do que profissionais (CANEL e SANDERS, 2012). Desse modo, a consecução das atividades da Assessoria de Comunicação precisa ser institucionalizada para dar garantia de continuidade em outras gestões, reforçando a profissionalização da atividade.

Strelow (2015), em pesquisa com assessorias de comunicação de empresas públicas do Estado do Rio Grande do Sul, percebeu que, na esfera pública, a comunicação supera o aspecto mercadológico e se apresenta como recurso fundamental para viabilizar a construção conjunta das políticas públicas entre os cidadãos e seus governantes. Segundo a autora, é responsabilidade dos comunicadores dos órgãos públicos promoverem a troca dialógica e permanente entre os governos e a sociedade. Mais do que informar, é importante que a comunidade tenha um canal aberto em que possa se expressar e se sentir representada.

Nesse sentido, Habermas (2003) reflete que a comunicação organizacional se sustenta na base do diálogo. Dessa maneira, o processo comunicativo deve permitir aos participantes da interação ou negociação, poder e direitos iguais de questionar o outro sem recorrer à coerção, com argumentações embasadas em racionalidade adequada ao contexto do evento.

Sob este prisma, Scimeoni (2009) afirma que o trabalho da assessoria de comunicação tem como princípio consultivo o conhecimento e a capacidade técnica dos profissionais que nela atuam. Portanto, devem ter autonomia de atuação, ou seja, cumprir tarefas sem sofrer veto, censura, controle ou obstrução, como já foi explicitado por Canel e Sanders (2012).

Alves (2015) corrobora essa visão quando diz que o espaço para a divulgação de informações é fundamental para a manutenção ou implantação da organização social. No entanto, para o autor, esse cenário não deve inibir a possibilidade de criar mecanismos em que existam espaços para uma relação dialógica. 
Uma das ferramentas de transmissão das expectativas da comunidade são os chamados houseorgans, dentre eles o jornal institucional, que se mantêm como "canal importante de relacionamento da empresa com os diversos públicos, em especial os colaboradores"; no entanto, as organizações "ou não avaliam de modo regular sua eficácia, baseadas em consultas frequentes aos públicos", ou, "quando o fazem, adotam uma metodologia caseira" que objetiva legitimar o que vem se fazendo (BUENO, 2003).

Alves (2015) fez um levantamento documental sobre a estrutura de comunicação em 59 universidades federais brasileiras. De acordo com o autor, uma questão importante relacionada à publicação do organograma refere-se à posição do setor de comunicação na estrutura organizacional. A proximidade com a administração superior é fundamental para assegurar que a comunicação aconteça no plano estratégico (ALVES, 2015). Essa proximidade garante não só a questão estratégica, mas também ajuda a construir a imagem de uma determinada instituição ou gestão, o que oportuniza ao gestor de comunicação auxiliar a administração no cumprimento das suas metas. Nesse sentido, o pesquisador verificou que a nomenclatura mais utilizada pelas universidades federais para designar o setor de comunicação é o de assessoria de comunicação $(55,6 \%)$. O termo assessoria está relacionado ao apoio às atividades de gestão e é descrito como "órgão, ou conjunto de pessoas, que assessoram um chefe" (HOUAISS e VILLAR, 2009, p.69). O termo assessoria não pode aqui ser reduzido a assessorar o chefe, mas sim à gestão, à construção da imagem institucional, dando transparência às ações e integrando à comunidade, portanto, de acordo com Alves (2015), é mais amplo que o apontado pelo dicionário.

Para Ferraretto e Ferraretto (2009) as assessorias de comunicação social apresentam serviço especializado que coordena todas as atividades de comunicação entre um cliente e seus públicos, por meio do estabelecimento de uma política específica e da aplicação de estratégias predefinidas, englobando ações nas áreas de jornalismo, relações públicas e publicidade e propaganda.

Na visão de Colombo (2009), o assessor de comunicação pode trabalhar em uma empresa, família, ONG, órgão governamental ou uma personalidade. Sua comunicação é institucional, ou seja, tem o objetivo de transformar a rotina de trabalho dos órgãos e empresas em notícia. Dotada de uma visão comercial, a assessoria de comunicação precisa racionalizar os custos para manter informado o seu público mais importante. Daí o uso privilegiado de e-mails, informativos eletrônicos e boletins, por exemplo.

Guerra (2009, p.29) afirma que, para atuar em um departamento de comunicação de uma empresa, o primeiro passo é conhecer a organização, "Afinal, você só pode falar daquilo que conhece muito bem. A dica é: vasculhe. Conheça a história da empresa, converse com as pessoas 
e a comunidade em que a empresa está inserida". Vos (2008) afirma que as competências mais citadas como pontos fortes que um profissional de comunicação devem possuir foram a percepção analítica e a empatia, além do conhecimento do grupo-alvo.

Almansa (2010) define assessoria de comunicação como uma estrutura organizada, subordinada diretamente à alta direção, que coordena e interliga todas as ações de comunicação para criar, manter, melhorar a imagem da organização perante os seus públicos. A mesma autora defende que na assessoria de comunicação se estabelecem estratégias eficazes com a finalidade de manter, consolidar ou melhorar a imagem corporativa de uma instituição. A comunicação interna permite a uma organização que as distintas partes permaneçam informadas e que todos sejam conhecedores daquilo que se sucede na sua cultura. Dessa maneira, os funcionários não precisam se inteirar dos acontecimentos de sua organização pelos meios de comunicação externos (ALMANSA, 2010).

O desenvolvimento de ações de comunicação interna só traz vantagens à organização. Sempre é positivo contar com uma equipe informada e conhecedora da realidade, porque isso se traduz em maiores níveis de motivação e responsabilidade, e, portanto, de produtividade (ALMANSA, 2010). É uma visão empresarial, mas que cabe ao contexto pesquisado na medida em que a visibilidade pode motivar o trabalho de cada um e potencializar maiores resultados e o retorno do investimento à população, os quais já foram mencionados anteriormente.

\section{Considerações Finais}

A literatura sobre a comunicação organizacional, em especial com ênfase em instituições públicas, encontra-se dispersa entre referenciais mais generalistas, o que torna desafiador e oportuno que outros levantamentos sobre o assunto possam ser feitos.

Em pesquisas realizadas anteriormente, Kunsch (1991) e Scroferneker (2001) em momentos e realidades diferentes, porém complementares, observam que a comunicação nas organizações ainda é incipiente, não sendo tratada como "elemento vital" e como uma "ferramenta estratégica". Sendo assim, outras pesquisas poderão contribuir aprofundando o entendimento da área de comunicação como importante às organizações e que não se esgota com a presente pesquisa.

Os desafios da comunicação no ambiente público passam, além da necessidade do olhar estratégico, pela transposição da barreira dos fatores políticos que influenciam no desempenho dos órgãos de comunicação institucional. Isto acontece uma vez que, como já mencionado por Canel e Sanders (2012), as instituições públicas podem sofrer mais interferências na gestão do 
que as congêneres do setor privado, pelas constantes trocas nas gestões por escolhas que priorizam influências pessoais à promoção de profissionais qualificados.

Há ainda a urgência em se dar um maior entendimento aos problemas de comunicação dentro das instituições. As diferenças de interesses entre os servidores, os gestores e os usuários dos órgãos públicos acabam por refletir na qualidade da comunicação. Mais do que a valorização dos discursos mal-ditos conceituados por Roman (2012), é impositivo ao profissional da comunicação uma melhor observação sobre esses questionamentos. Desta forma, é possível entender os anseios e promover uma comunicação mais alinhada com o interesse institucional e não apenas de uma parte do público.

A despeito da falta de investimento em pessoal apontada em pesquisas na área pública, faz-se necessário criar soluções de baixo custo e que envolvam o público para proporcionar interação e consequente melhoria não só da imagem, mas dos rendimentos da organização. Do mesmo modo, as assessorias de comunicação, entendidas como unidades estratégicas e de apoio à gestão, devem ter uma política de comunicação que não reflita apenas a imagem e os desejos dos gestores das instituições e sim de toda a organização, obedecendo aos princípios legais concernentes ao assunto. Aos profissionais que trabalham na área é necessário, além do conhecimento sobre o local de atuação e a capacidade técnica, entenderem como a comunicação acontece dentro de sua instituição, tanto formalmente quanto informalmente, para melhor entendimento de estratégias futuras para uma comunicação plena e integrada.

\section{Referências}

AlmANSA, Ana. Assessorias de Comunicação. São Caetano do Sul, SP: Difusão Editora, 2010.

ALVES, Cristiano Alvarenga. Gestão da Comunicação das Universidades Federais: mapeamento das ações e omissões. 161p. Dissertação (Mestrado em Comunicação) - UNESP, BauruSP, 2015. Disponível em: https://repositorio.unesp.br/handle/11449/126510. Acesso em 15 jun.2017.

BALDISSERA, Rudimar. Comunicação organizacional: o treinamento de recursos humanos como rito de passagem. São Leopoldo: Ed. da Unisinos, 2000.

BRASIL. Constituição Federal de 1988. Promulgada em 5 de outubro de 1988. Disponível em: http://www.planalto.gov.br/ccivil_03/Constituicao/Constituicao.

htm. Acesso em: 28 maio2017.

BUENO, Wilson da Costa. Comunicação empresarial: teoria e prática. Barueri: Manole, 2003.

CANEL, Maria Jose. SANDERS, Karen. Government Communication: An Emerging Field in Political Communication Research. In: The SAGE Handbook of Political Communication, 2012. Disponível em: http://mariajosecanel.com/pdf/e

mergingfield.pdf. Acesso em: 12 maio 2017. 
COLOMBO, Irineu Mario (Org.). Assessoria de Comunicação - Empresa, governo e terceiro setor. Curitiba: Desenhos e Letras, 2009.

COSTA, Dayane Jesus da. A Autarquia na Administração Pública Indireta. 2012. Disponível em: http://www.egov.ufsc.br/portal/conteudo/autarquia-na-administração-pública-indireta. Acesso em: 12 jun. 2017.

CRUZ, Cassiana Maris Lima. Comunicação Organizacional e pressupostos de comunicação integrada: a experiência em uma universidade na implementação/reestruturação do jornal institucional. Conexão - Comunicação e Cultura, v. 6, n. 11, p. 193-209, jan./jun. 2007. Disponível em: http://www.ucs.br/etc/revistas/index.php/conexao/article/viewFile/199/190. Acesso em: 12 jun. 2017.

DEVERELL Edward. OLSSON, Eva-Karin. WAGNSSON, Charlotte. HELLMAN, Maria. JOHNSSON, Magnus. Understanding public agency communication: The case of the Swedish armed forces. United Kingdom Journal of Public Affairs, 2015. Disponível em: https://onlinelibrary.wiley.com/doi/abs/10.1002/pa.1552. Acesso em: 12 maio 2017.

FERRARETTO, Elisa Kopplin; FERRARETTO, Luiz Artur. Assessoria de imprensa: teoria e prática. São Paulo: Summus, 2009.

GERZSON, Vera R. S.; MÜLLER, Karla M. Procac/Canoas: comunicação pública e relacionamento com o cidadão. Revista Famecos: Mídia, Cultura e Tecnologia, v. 1, n. 38, p. 62-68, abr. 2009.2 Disponível em: http://revistaseletronicas.pucrs.br/ojs/index.php/revistafamecos/article/view/5302. Acesso em: 12 maio 2017.

HABERMAS, Jurgen. Consciência moral e agir comunicativo. 2. Ed. Rio de Janeiro: Tempo Brasileiro, 2003.

HOUAISS, Antônio; VILLAR, Mauro de Salles. Dicionário Houaiss de Língua Portuguesa. Instituto Antônio Houaiss de Lexicografia e Banco de Dados da Língua Portuguesa S/C Ltda. Rio de Janeiro: Objetiva, 2009.

IASBECK, Luiz Carlos. Discurso e texto: a produção da expressão nas organizações. In: OLIVEIRA, Ivone de Lourdes; MARCHIORI, Marlene (Org.). Comunicação, discurso e organizações. São Paulo: Difusão Editora, 2013. p. 71- 86.

IASBECK, Luis Carlos Assis. Identidade organizacional e a construção de discursos institucionais.In: KUNSCH, Margarida M. Krohling (org). Comunicação Organizacional: Linguagem, gestão e perspectivas. Volume 2. São Paulo: Saraiva, 2012. p.7-30.

KUNSCH, Margarida Maria Krohling. A Comunicação como fator de humanização das organizações. São Caetano do Sul, SP: Difusão Editora, 2010.

KUNSCH, Margarida Maria Krohling. Universidade e comunicação na edificação da sociedade. São Paulo: Loyola, 1992.

MARCHIORI, Marilene Regina. As interconexões entre cultura organizacional e comunicação. In KUNSCH, Margarida M. Krohling (org). Comunicação Organizacional: Linguagem, gestão e perspectivas. Volume 2. São Paulo: Saraiva, 2012. p.293-320.

MARCHIORI, Marilene Regina. Cultura e Comunicação Organizacional: um olhar estratégico sobre a organização. 2. ed. São Caetano do Sul (SP): Difusão Editora, 2008.

MOTA, Iraê Perreira et al. Assessoria de imprensa: cenário de negócios e convergência tecnológica. Temática, João Pessoa, v. 5, p.1-11, maio 2011. Disponível em:http://periodicos.ufpb.br/ojs2/index.php/tematica/article/view/30212/15974.

Acesso em: 12 jun. 2017. 
NASSAR, Paulo. Política e Comunicação - A comunicação com pensamento. In: Nassar, Paulo (org.). Comunicação Empresarial: estratégia das organizações vencedoras. São Paulo: Aberje Editorial, 2005.

REINALDO, Priscila; MAYER, Verônica Feder; NOGUEIRA, Heloisa Guimarães Peixoto. Comunicação no âmbito da gestão pública: O caso de uma autarquia pública brasileira. In: XXIV ENCONTRO NACIONAL DA ANPAD, 2010, Rio de Janeiro. Artigo. Rio de Janeiro: Anpad, 2010. p. 1 - 17. Disponível em: http://www.anpad.org.br/admin/pdf/apb1509.pdf. Acesso em: 12 jun. 2017.

ROMAN, Artur Roberto. Organizações: um universo de discursos bem-ditos, mal-ditos e nãoditos. In:KUNSCH, Margarida M. Krohling (org). Comunicação Organizacional: Linguagem, gestão e perspectivas. Volume 2. São Paulo: Saraiva, 2012. p.125-158.

SCROFERNEKER, Cleusa Maria Andrade. Os (des) caminhos da comunicação na implantação do programa de qualidade total da universidade brasileira. Educação Brasileira, v. 23, n. 46, p. 75-91, jan./jun. 2001.

SILVA, Joelma Soares da; PINTO, Francisco Roberto; ROCHA, Jakcilene Dias; BARROS, Conceição de Maria Pinheiro. A relação entre comunicação organizacional Interna e motivação: um estudo de caso em Uma instituição de ensino superior. Revista Expectativa, v.11. n. 11, 2012, p. 123 - 143. Disponível em e-revista.unioeste.br/index.php/expectativa/article/view/7278. Acesso em 15 jun. 2017.

STRELOW, Patrícia Hammes. Comunicação, relações e culturas: as assessorias de imprensa no tecer complexo das organizações públicas. Dissertação (Mestrado em Comunicação Social) Faculdade de Comunicação Social, Pontifícia Universidade Católica do Rio Grande do Sul (PUCRS) - Porto Alegre, 2015. Disponível em: repositorio.pucrs.br/dspace/handle/10923/7063. Acesso em: 12 maio 2017.

TEGONI, Andréia Cristina. Comunicação interna, diferenciação, integração e fragmentação na cultura organizacional em uma instituição particular de ensino superior. Dissertação (mestrado em Administração). Pontifícia Universidade Católica do RioGrande do Sul. Porto Alegre, 2015. Disponível em:http://repositorio.pucrs.br/dspace/handle/10923/7561. Acesso em: 15 jun. 2017.

TORQUATO, Francisco Gaudêncio. Tratado de comunicação organizacional e política. São Paulo: Pioneira Thomson Learning, 2004.

UNIVERSIDADE FEDERAL DO PARANÁ. Relatório De Pessoal Ativo Por Cargo. PróReitoria de Gestão de Pessoas da Universidade Federal do Paraná. Disponível em: http://www.progepe.ufpr.br/progepe/dadostabe/RELATORIO

\%20DE\%20PESSOAL\%20ATIVO\%20POR\%20CARGO.pdf. Acesso em: 28 maio 2017.

VOS, Marita. WESTERHOUDT, Evelyn. (2008). Trends in government communication in The Netherlands. Journal of Communication Management, p. 18-29. Disponível em: https://www.emerald.com/insight/content/doi/10.1108/136325

40810854217/full/html. Acesso em: 12 maio 2017.

Recebido em 30/04/2020 - Aprovado em 10/07/2020. 